\title{
Safety and efficacy of magnetic seed localisation of non-palpable breast lesions: pilot study in a Chinese population
}

\author{
WY Fung *, T Wong, CM Chau, Ellen LM Yu, TS Chan, Rois LS Chan, Alfred WT Yung, Johnny KF Ma
}

This article was published on $11 \mathrm{Dec}$ 2020 at www.hkmj.org.

\section{A B S T R A C T}

Introduction: A magnetic seed marker system (Magseed, Endomagnetics, Cambridge, United Kingdom) is used as a localisation method for nonpalpable breast lesions in the United States, Europe, and Hong Kong. It overcomes many limitations of conventional techniques and allows scheduling flexibility. We sought to evaluate its efficacy and safety in the Chinese population.

Methods: We retrospectively reviewed all Chinese women who underwent magnetic seed markerguided breast lesion excision from June 2019 to February 2020 at a single institution. Placement success (final target-to-seed distance $<10 \mathrm{~mm}$ ) was evaluated by imaging on the day of surgery. Specimen radiographs and pathology reports were reviewed for magnetic seed markers and target removal. Margin clearance and re-excision rates were analysed.

Results: Twenty two magnetic seed markers were placed in 21 patients under sonographic or stereotactic guidance to localise 21 target lesions. One target lesion required two magnetic seed markers for bracketing. There was no migration of nine markers placed 6 to 56 days before the day of surgery. Placement success was achieved in $20(90.9 \%)$ cases. Mean final target-to-seed distance was $3.1 \mathrm{~mm}$. Two out of 21 (9.5\%) lesions required alternative localisation due to marker migration $\geq 10 \mathrm{~mm}$, while 19 (90.5\%) lesions underwent successful magnetic seed marker-guided excision. Three of these 19 lesions (15.8\%) were excised with therapeutic intent, one of which $(33 \%)$ required re-excision due to a close margin. All 22 magnetic seed markers were successfully removed. No complications were reported.

Conclusion: Magnetic seed markers demonstrated safety and efficacy in Chinese women for breast lesion localisation and excision.

\section{Hong Kong Med J 2020;26:500-9}

https://doi.org/10.12809/hkmj208559

\author{
1 WY Fung * ${ }^{*}, \mathrm{MB}, \mathrm{ChB}, \mathrm{FRCR}$ \\ ${ }^{1} \mathrm{~T}$ Wong, MB, ChB, FHKCR \\ ${ }^{1} \mathrm{CM}$ Chau, MB, BS, FHKCR \\ ${ }^{2}$ ELM Yu, BSc, MSc \\ ${ }^{1}$ TS Chan, MB, BS, FHKCR \\ ${ }^{1}$ RLS Chan, MB, BS, FHKCR \\ ${ }^{1}$ AWT Yung, MB, BS, FHKCR \\ ${ }^{1} \mathrm{JKF}$ Ma, MB, BS, FHKCR
}

Department of Radiology, Princess Margaret Hospital, Hong Kong

Clinical Research Centre, Princess Margaret Hospital, Hong Kong

* Corresponding author: fwyyuk@gmail.com

New knowledge added by this study

- The magnetic marker system is an accurate and safe method to localise and excise non-palpable breast lesions.

- This is the first study reporting high placement success and retrieval rate without any reported complications in a Chinese population.

Implications for clinical practice or policy

- The magnetic marker system addresses many limitations associated with conventional localisation methods such as hookwire and radioguided occult lesion localisation. The deployment procedure is approved to be performed up to 30 days before the surgical procedure in Hong Kong, and as long-term implantation in the United States and Europe.

- The lack of any external component overcomes the disadvantages of wire localisation including wire kinking, transection, migration, and breakage.

- Magnetic seed markers are non-radioactive, thus no support from the nuclear medicine unit is necessary and radiation exposure to staff and patients can be minimised.

\section{Introduction}

With the increasing use of screening mammography and advances in neoadjuvant therapy, tumours at the time of surgery are more often non-palpable. ${ }^{1-7}$ Accurate image-guided localisation is the key to successful excision of these lesions.
Hookwire localisation has been the traditional standard method of localising non-palpable breast lesions for decades. It has many inherent limitations and challenges. Wire placement has to be done on the day of surgery to minimise the risk of wire dislodgment, which limits the flexibility of radiology 
appointments and scheduling of surgery, therefore potentially resulting in delayed surgery. ${ }^{8}$ Wire displacement and wire transection with retained fragments have also been reported. ${ }^{5,9,10}$ The track of the wire limits the surgical approach, causing additional healthy breast tissue to be dissected along the course of the wire. ${ }^{5,9,10}$ These can affect cosmetic outcome. . $^{5,9,10}$

More recently, radioguided occult lesion localisation (ROLL) has gained popularity, as it overcomes many disadvantages of wire localisation and is reported to be equally effective compared with hookwire. ${ }^{11}$ However, it also needs to be performed on the same day or a day before surgery due to the half-life of the radiotracer. ${ }^{12}$ Moreover, radiation safety precautions and the need of Nuclear Medicine unit support limit its widespread use.

Recently, non-radioactive non-wire techniques have started to emerge and address many of these issues. A magnetic marker system (Magseed, Endomagnetics, Cambridge, United Kingdom) is one of these techniques and received clearance for longterm breast implantation from United States Food and Drug Administration in February 2018. It was introduced in Hong Kong in 2019. Our study aimed to evaluate the efficacy and safety of magnetic seed marker localisation of non-palpable breast lesions. To the best of our knowledge, there is no prior publication on magnetic seed marker localisation in a Chinese population.

\section{Methods}

A retrospective review of all Chinese women who underwent magnetic seed marker localisation for non-palpable breast lesions from June 2019 to February 2020 in a single institution was conducted. Patients were selected by breast surgeons and breast radiologists in consensus by reviewing images on the basis of target visibility and target depth. Patients who had a magnetic seed marker placed but surgery performed out of the study period were excluded.

\section{Magnetic marker system}

The magnetic seed marker (Magseed, Endomagnetics, Cambridge, United Kingdom) is made of nonradioactive paramagnetic low-nickel stainless steel. The seed is $5 \mathrm{~mm} \times 0.9 \mathrm{~mm}$, which is the smallest non-wire non-radioactive localisation device available. The magnetic seed marker is preloaded in a sterile 7- or 12-cm 18-gauge deployment needle.

The magnetic seed marker is intended to be placed at a depth up to $3 \mathrm{~cm}$ from the skin according to the manufacturer's instructions ${ }^{13}$ due to limitations of signal transmission from a greater depth. It is localised with a detector probe (Sentimag, Endomagnetics), which generates an alternating magnetic field to transiently magnetise the seed..$^{14}$

\section{乳腺病灶定位標記物用於無腫塊乳腺病灶患者的 效度和安全性：華籍人口初步研究 \\ 馮惠鈺、黃婷、周智敏、余洛汶、陳庭笙、陳樂詩、翁維德、 馬嘉輝}

引言：在美國、歐洲和香港, 乳腺病灶定位標記物（Magseed）用於 定位無腫塊乳腺病灶。這種標記物克服了許多常規技術的限制, 並允 許調度靈活性。本研究評估乳腺病灶定位標記物在華籍人口中的效度 和安全性。

方法：這項回顧性研究納入從2019年6月至2020年2月期間在單一中 心接受乳腺病灶定位標記物引導下乳腺病灶切除術的所有華籍婦女, 通過成像評估手術時標記物放置成功與否 (即靶病灶與標記物相距 $10 \mathrm{~mm}$ 以下) 。對標本 $X$ 光片和病理報告進行審查, 以了解標記物和 靶病灶切除情況, 並分析切緣陽性和再切除率。

結果：在超聲或立體定向引導下, 對 21 例患者放置22個乳腺病灶定 位標記物, 以定位 21 個標靶病灶, 其中一個標靶病灶需要兩個標記 物進行包圍。手術前6天到 56 天放置的9個標記物沒有移位。共20例 (90.9\%) 成功放置標記物, 而標記物與標靶病灶平均相距 3.1 毫米。 21 例病灶中, 2 例（9.5\%）因標記物移位 $10 \mathrm{~mm}$ 或以上需要替代定 位, 其餘19例（90.5\%）成功進行標記物引導下切除。這19例病灶 中, 3例 $(15.8 \%)$ 出於治療目進行切除, 其中1例（33\%）由於切緣 狹窄須再次進行切除。所有 22 個標記物均成功移除。沒有併發症的報 告。

結論：研究結果顯示乳腺病灶定位標記物對華籍婦女進行乳腺病灶定 位和切除安全和有效。

A visual numerical value and audio feedback are produced according to the strength of the magnetic field, thus signalling the distance of the seed from the detector probe..$^{14}$

\section{Localisation procedure}

Magnetic seed marker placement was percutaneously performed under image guidance by one of four breast radiologists with 3 to 19 years of experience performing image-guided breast localisation, or by a breast radiology trainee who was directly supervised by one of the breast radiologists. During ultrasound-guided placement, the patient lies supine and rolled slightly with a wedge put under the shoulder on the ipsilateral side to spread the breast evenly. The ipsilateral arm is raised over the patient's head to facilitate a larger sterilisation field. During stereotactically guided placement, the patient lies on either side or sits up to facilitate breast compression by the stereotactic table.

Target-to-seed distance was evaluated in real time for magnetic seed markers placed under sonographic guidance and was measured on postprocedure mammograms in mediolateral and craniocaudal projections for magnetic seed markers placed under stereotactic guidance. If multiple magnetic seed markers were placed in one breast, the minimum distance between the markers was 
measured. For patients with magnetic seed markers inserted before the day of surgery, target ultrasound and/or mammography were performed on the day of surgery to evaluate for any delayed magnetic seed marker migration, which was defined by any difference between the initial target-to-seed distance after the localisation procedure and the final target-

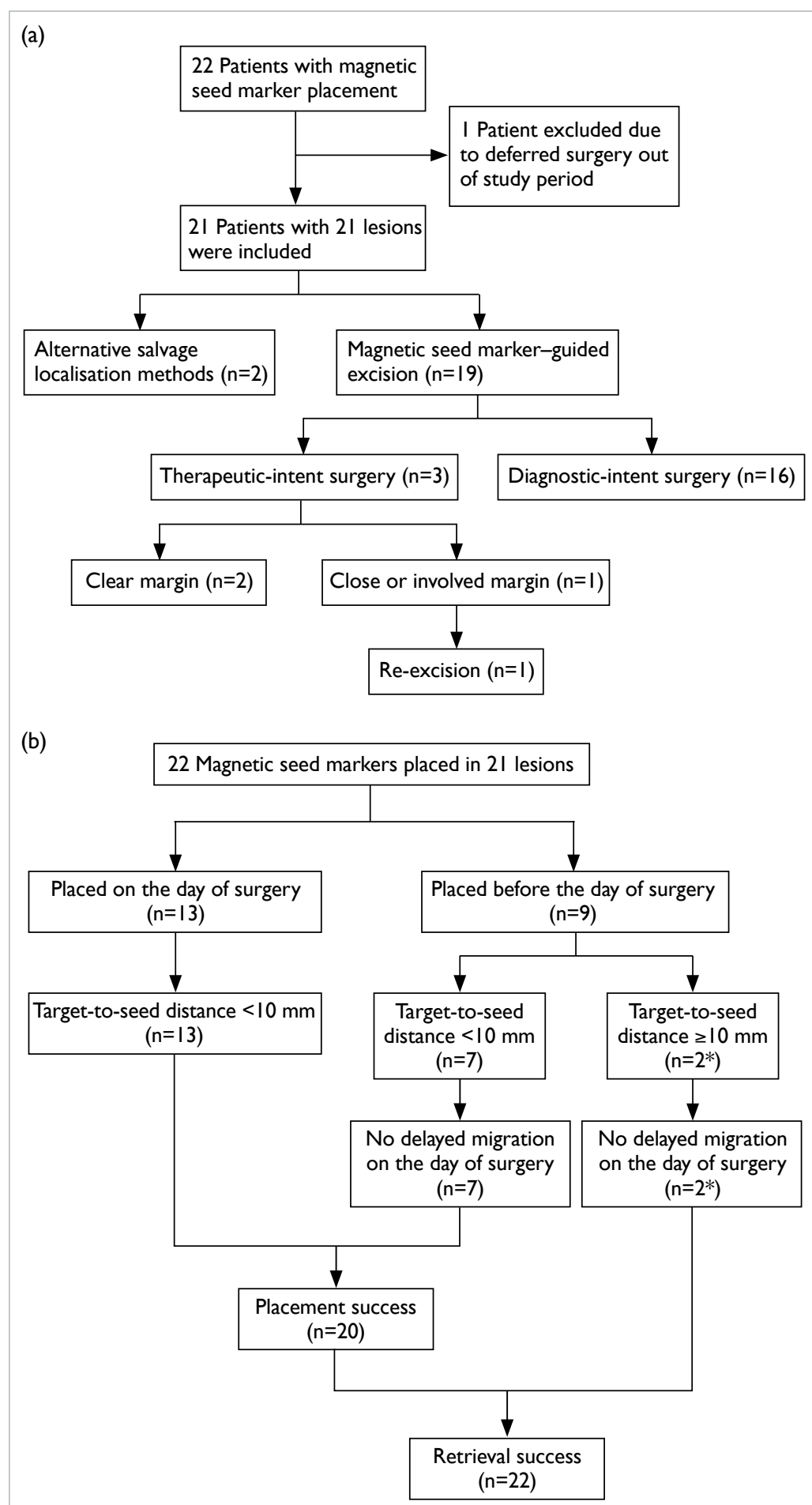

FIG I. (a) Flowchart showing subject recruitment and outcome. (b) Outcomes of the 22 magnetic seed markers placed in the 2I target lesions

* Included one additional magnetic seed marker for bracketing to-seed distance on the day of surgery. If the final target-to-seed distance was $\geq 10 \mathrm{~mm}$, signifying significant migration, alternative localisation was performed on the day of surgery. Lesions with acceptable marker position underwent markerguided excision as planned with the depth of the marker from the skin evaluated by preoperative ultrasound, followed by intraoperative guidance with the use of the probe. The presence of the markers in the specimens was confirmed with the probe by surgeons and by specimen radiographs with the radial margins evaluated.

\section{Outcome analysis}

Rates of placement success and retrieval success with a 95\% confidence interval (CI) were calculated using the Wilson score method. ${ }^{15}$ Placement success was defined as a final target-to-seed distance $<10 \mathrm{~mm}$ in any plane on images on the day of surgery, with reference to guidelines from the National Health Service Breast Screening Programme ${ }^{16}$ and previous studies. $^{14,17}$ For degrees of magnetic seed marker placement success, the final target-to-seed distances were further subdivided into $\leq 1 \mathrm{~mm}, 2$ to $5 \mathrm{~mm}$, and 5 to $9 \mathrm{~mm}$. Retrieval success was determined by the presence of the magnetic seed marker(s) in the specimen radiograph.

Electronic patient records were reviewed for patients' demographics, preoperative pathology (if any), and indications for surgery. Specimen radiographs and pathology reports were reviewed to verify excision of target lesions and to evaluate the resection margins.

The target lesions were divided into two groups according to the indications for surgery. The surgery was considered to be of therapeutic intent if the target lesion had been proven to be malignant from preoperative pathology. Otherwise, the surgery was considered to be of diagnostic intent. Among the surgeries with therapeutic intent, margin clearance, defined as at least 1-mm disease-free margins, was assessed. The re-excision rate due to inadequate margin clearance was analysed. Complications related to magnetic seed marker deployment and surgeries were recorded.

\section{Results}

There were 22 Chinese patients with magnetic seed markers placed during the study period; one patient was excluded due to deferred surgery out of the study period (Fig 1a). A total of 21 patients, with mean age 60.0 years (range, 38-73 years) were included (Table 1$)$. Thirteen patients $(61.9 \%)$ each had one magnetic seed marker placed on the day of surgery, which were performed during the initial learning period of this new technique. Eight patients (38.1\%) had nine magnetic seed markers inserted before the day of surgery in out-patient 
TABLE I. Characteristics of subjects and target lesions $(n=2 I)^{*}$

\begin{tabular}{|c|c|}
\hline Age, y & $60.0 \pm 11.6$ \\
\hline $\begin{array}{l}\text { Time between magnetic seed marker } \\
\text { placement and surgery, } d\end{array}$ & $5.6 \pm 12.4$ \\
\hline $\begin{array}{l}\text { Lesions with magnetic seed markers } \\
\text { placed before the day of surgery }\end{array}$ & $8(38.1 \%)$ \\
\hline \multicolumn{2}{|l|}{$\begin{array}{l}\text { Image-guidance modality for magnetic } \\
\text { seed marker insertion }\end{array}$} \\
\hline Ultrasound & 15 (71.4\%) \\
\hline Stereotactic & $6(28.6 \%)$ \\
\hline \multicolumn{2}{|l|}{ Target type } \\
\hline Masses & $15(71.4 \%)$ \\
\hline Microcalcifications & $3(14.3 \%)$ \\
\hline Biopsy marker & $1(4.8 \%)$ \\
\hline Architectural distortion & $1(4.8 \%)$ \\
\hline Focal asymmetry & $1(4.8 \%)$ \\
\hline \multicolumn{2}{|l|}{ Excision guidance } \\
\hline Alternative salvage localisation methods & $2(9.5 \%)$ \\
\hline Magnetic seed marker-guided excision & 19 (90.5\%) \\
\hline Diagnostic intent & $16(84.2 \%)$ \\
\hline Therapeutic intent & $3(15.8 \%)$ \\
\hline
\end{tabular}

setting, ranging from 6 to 56 days from surgery with a median of 8 days (interquartile range $=6.25-13.75$ ) [Fig 1b]. Fifteen out of 22 magnetic seed markers (68.2\%) were placed under ultrasound guidance, and seven magnetic seed markers $(31.8 \%)$ were placed under stereotactic guidance. The most common type of target lesion was a solid mass (15 of 21, 71.4\%), all of which had markers placed under ultrasound guidance. The other six lesions had magnetic seed markers placed by stereotactic guidance, including three groups of microcalcifications, one biopsy marker, one architectural distortion, and one focal asymmetry. One group of calcifications required two magnetic seed markers for bracketing due to its extensive distribution.

Two magnetic markers (9.1\%) migrated $\geq 10 \mathrm{~mm}$ away from their targets. Both had been placed under stereotactic guidance and migrated along the direction of breast compression (Fig 2). One of these magnetic seed markers was aimed for bracketing initially. No delayed migration was detected in all of the nine magnetic seed markers placed before the day of surgery, and there was no further migration of the two with initial migration. Among the 22 magnetic seed markers, 17 (77.3\%) and three (13.6\%) were $\leq 1 \mathrm{~mm}$ and 2 to $5 \mathrm{~mm}$ from their target, respectively (Figs 3 and 4). Therefore, placement success was achieved in 20 out of 22 magnetic seed markers, with a success rate of $90.9 \%$ (95\% CI=72.2\%-97.5\%). The mean final target-to-seed distance was $3.1 \pm 9.8 \mathrm{~mm}$
(Table 2). The final distance between the two bracketing magnetic seed markers was $29 \mathrm{~mm}$. All 22 magnetic seed markers were able to be localised by the probe intraoperatively and removed successfully (100\%; 95\% CI=85.1\%-100\%).

Two out of 21 lesions $(9.5 \%)$ required alternative localisation performed on the day of surgery to guide lesion excision due to significant magnetic seed marker migration of $\geq 10 \mathrm{~mm}$. One of the lesions was a mammographic architectural distortion that could be visualised on ultrasound. The magnetic seed marker had migrated $13 \mathrm{~mm}$ laterally on mammogram. Ultrasound-guided skin marking was performed on the day of surgery with the magnetic seed marker detected and removed together with successful removal of the target lesion (Fig 2). Another lesion was a wide distribution of microcalcifications that required two magnetic seed markers for bracketing under stereotactic guidance. One of the magnetic seed markers migrated $45 \mathrm{~mm}$ along the direction of breast compression, with no significant associated haematoma. Salvage hookwire localisation was performed on the day of surgery. The target lesion and the non-migrated magnetic seed marker were first removed by hookwire guidance, and the migrated magnetic seed marker was then detected by the probe and removed.

Nineteen lesions (90.5\%) had magnetic seed marker-guided excision as planned, with sonographic depth of the magnetic seed markers from skin ranging from 3 to $21 \mathrm{~mm}$ with a mean of $10.8 \pm 4.8 \mathrm{~mm}$. Among these 19 lesions, 16 (84.2\%) were excised with diagnostic intent and three $(15.8 \%)$ were excised with therapeutic intent.

For the 16 lesions excised with diagnostic intent, preoperative biopsies or fine needle aspiration had been performed in $14(87.5 \%)$ lesions. Core needle biopsy of 12 lesions, resulted in two with nondiagnostic findings, four with benign pathologies and six with high-risk findings; including four papillary lesions, one atypical ductal hyperplasia, and one with scanty atypical ductal cells. Fine needle aspiration was performed in two lesions, detecting one fibroadenoma and one papillary lesion. In final surgical pathology, two of these 16 lesions (12.5\%) had a malignant upgrade from the core biopsy findings including one low-grade and one highgrade ductal carcinoma in situ (DCIS).

For the three lesions excised with therapeutic intent, both preoperative biopsy and final surgical pathology showed DCIS. The subtype of these lesions included a high-grade DCIS, a low-grade DCIS, and an intermediate-grade DCIS with atypical lobular hyperplasia. One of them had close $(0.5 \mathrm{~mm})$ margins and required re-excision, for a margin clearance rate of $66.7 \%$ and a re-excision rate of $33.3 \%$. There were no reported complications related to magnetic seed marker localisation or lesion excision. 

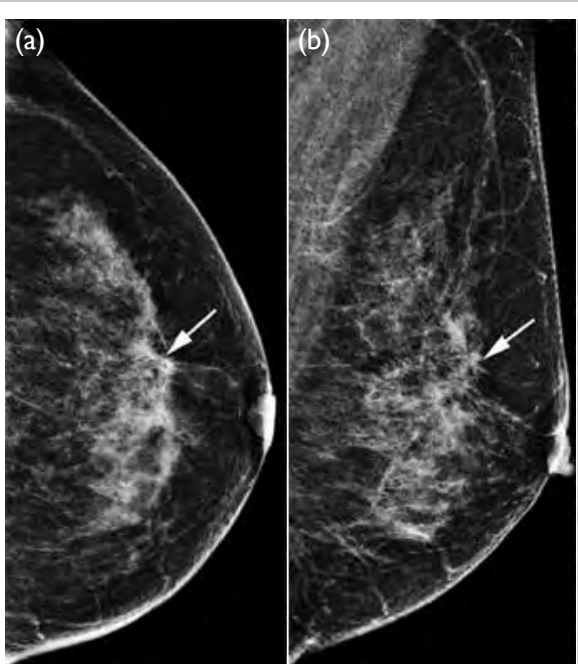

(d)

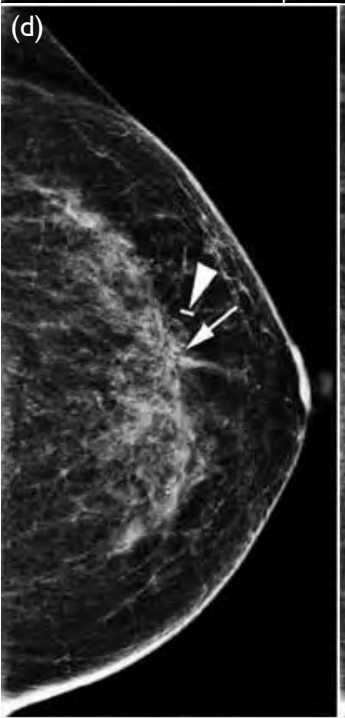

(h)
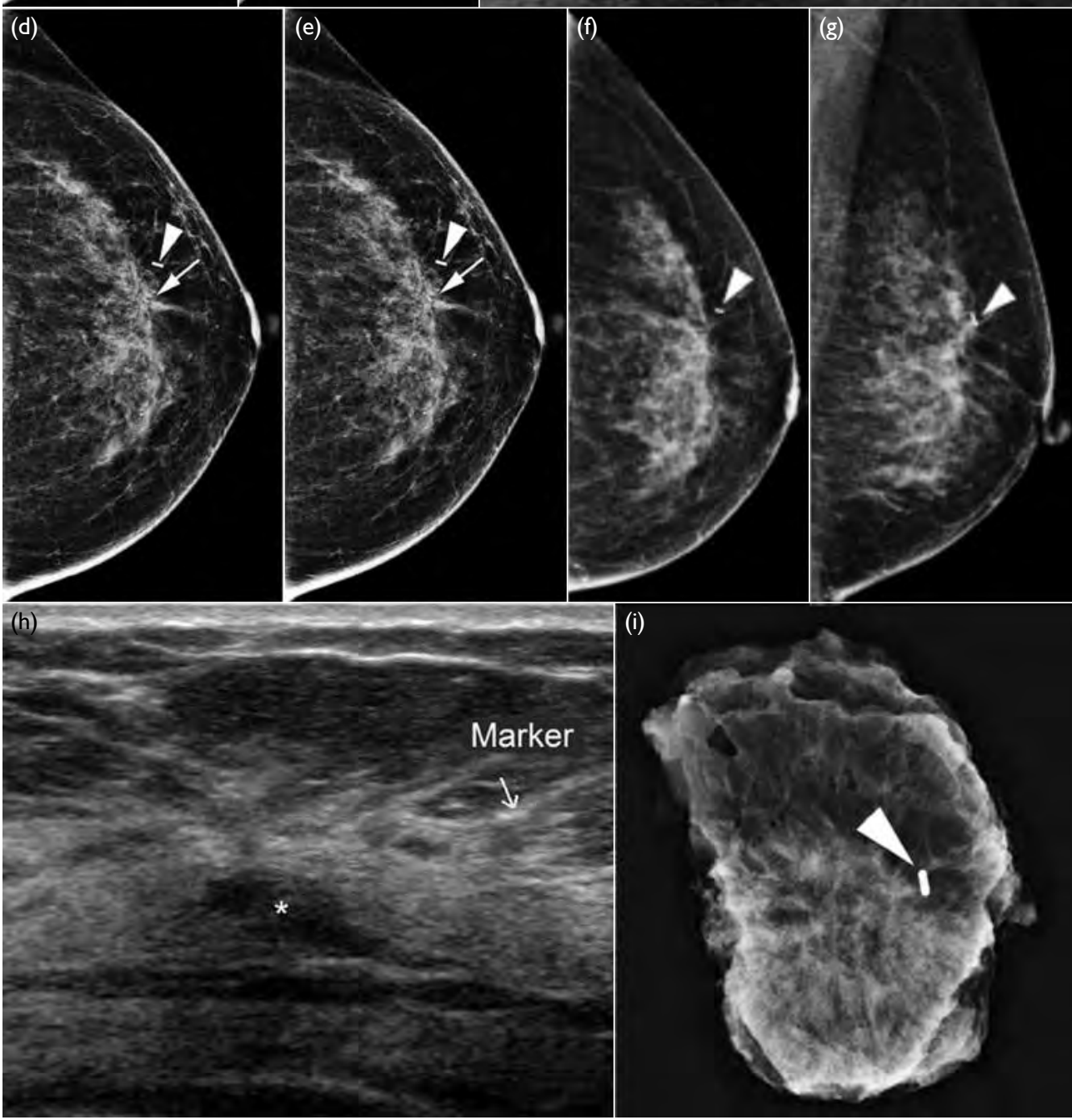

FIG 2. Mammographic craniocaudal (a) and mediolateral oblique (b) views of a 63-year-old woman showing an architectural distortion (arrows) in the upper outer quadrant of the left breast with lobular neoplasia on biopsy. Ultrasound of the left breast (c) showing a hypoechoic lesion (asterisk) at 12 o'clock. The operator decided to place the magnetic seed markers under stereotactic guidance with a lateromedial approach as the lesion was more discrete on mammogram. Post-procedure craniocaudal (d) and mediolateral (e) views reveal I3-mm lateral migration of magnetic seed markers (arrowheads) from the target (arrows). The migration was along the direction of breast compression, with no significant hematoma; this was likely due to the accordion effect. Craniocaudal $(f)$ and mediolateral $(g)$ views on the day of surgery showing no further delayed migration of the magnetic seed marker (arrowheads). Target ultrasound on the day of surgery ( $h$ ) showed that the magnetic seed marker was lateral to the hypoechoic lesion, which corresponded to the mammographically seen architectural distortion. Ultrasoundguided skin marking was done to localise hypoechoic lesion. The magnetic seed marker (arrowhead) was successfully detected intraoperatively and removed (i) 


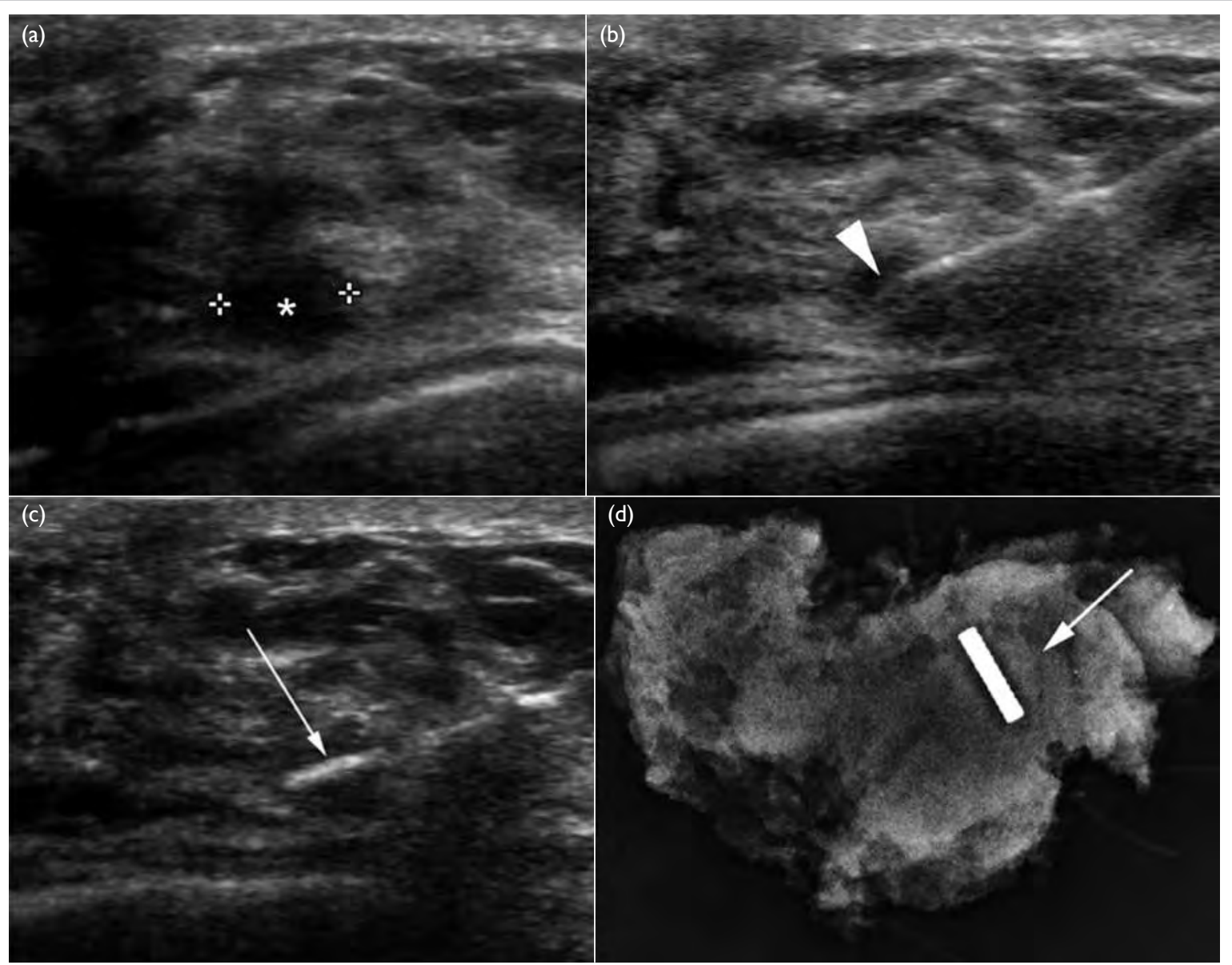

FIG 3. (a) Ultrasound of left breast of a $5 \mathrm{I}$-year-old woman showing an irregular 6-mm hypoechoic lesion with indistinct margins (asterisk) at 6 o'clock. Ultrasound-guided magnetic seed marking of the hypoechoic lesion was performed.The introducer needle tip (b, arrowhead) is at the centre of the lesion. Subsequent ultrasound (c) showing magnetic seed marker (arrow) in the centre of the lesion. Specimen radiograph (d) showing the magnetic seed marker (arrow), suggestive of a successful excision. The pathology of both biopsy and surgical specimens showed intraductal papilloma

\section{Discussion}

Successful localisation of breast lesions by magnetic seed markers was achieved in 19 out of 21 (90.5\%) Chinese patients with a high placement success rate (90.9\%) in our study. The majority of the magnetic seed markers were accurately placed with a mean final target-to-seed distance of $3.1 \mathrm{~mm}$. All of the successfully placed magnetic seed markers were $<5 \mathrm{~mm}$ of the target, with $85 \%$ of them $\leq 1 \mathrm{~mm}$. In all, 100\% marker retrieval was achieved without any reported complications. Such results were similar to several recent studies which revealed $100 \%$ successful magnetic seed marker retrieval ${ }^{14,17-20}$ and high placement success (96.7\%-100\%). ${ }^{14,17,18}$ Our re-excision rate for therapeutic intent surgery was found to be $33.3 \%$, which was apparently higher than that reported in previous studies, ranging from $14.8 \%$ to $21.9 \% .^{17-19}$ This could be attributable to our small sample size with only three lesions excised for therapeutic intent. In fact, a prospective nonrandomised control study by Zacharioudakis et $\mathrm{al}^{19}$ with 100 patients in each arm demonstrated that the outcome of magnetic seed marker localisation was comparable to hookwire localisation for breast conservation surgery in terms of re-excision rate. A systemic review by Fusco et $\mathrm{al}^{21}$ demonstrated that the successful localisation and margin clearance rates were $65 \%$ to $100 \%$ and $58 \%$ to $84 \%$, respectively for hookwire localisation, and $93 \%$ to $100 \%$ and $60 \%$ to $100 \%$, respectively for ROLL, while the margin clearance rates from other previous studies ${ }^{9,10,22}$ ranged from $57 \%$ to $87.4 \%$ for hookwire localisation and $75 \%$ to $93.5 \%$ for ROLL. All these suggest that magnetic seed marker is a feasible alternative localisation method.

Thirteen magnetic seed markers (59.1\%) were placed on the day of surgery during our initial experience. The purpose was to ensure safety and to allow radiologists' and surgeons' familiarisation with the new device and workflow. Among all of the nine magnetic seed markers placed before the day of surgery (range, 6-56 d), none of them showed delayed 


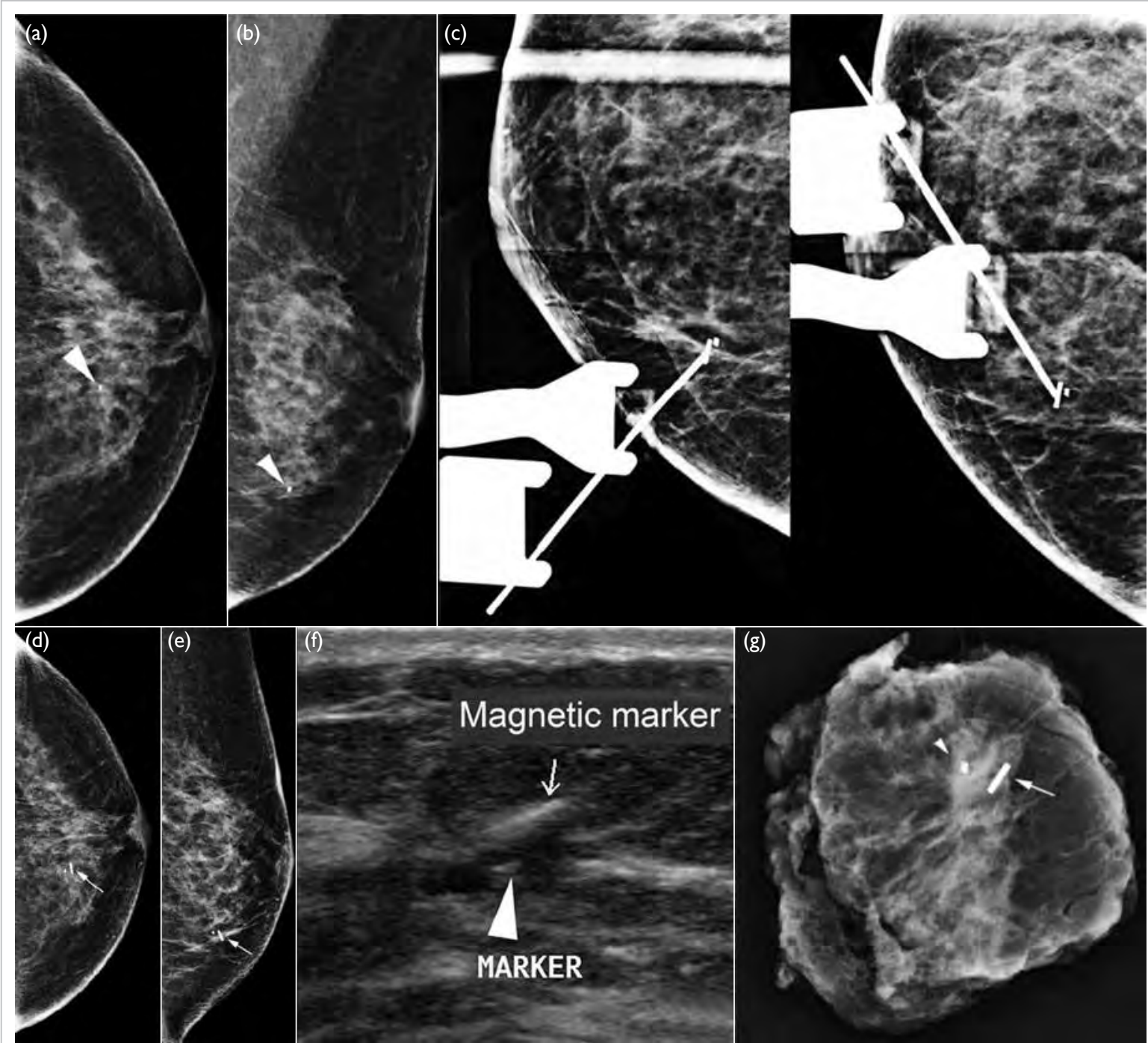

FIG 4. Mammogram with craniocaudal (a) and mediolateral oblique (b) views of a 56-year-old woman who had biopsy-proven high-grade ductal carcinoma in situ in the lower inner quadrant of the left breast with an open coil biopsy marker (arrowheads) placed upon prior stereotactic-guided biopsy. Stereotactic-guided placement of a magnetic seed marker was performed with the tip of the deployment needle targeting the biopsy marker (c). Post-procedure left mammogram of craniocaudal (d) and mediolateral (e) views, and supplementary ultrasound (f) showing the successful localisation of the biopsy marker. Specimen radiograph (g) confirmed the presence of both magnetic seed marker (arrow) and biopsy marker (arrowhead), suggestive of a successful excision of target lesion. Pathology of the final surgical specimen showed high-grade ductal carcinoma in situ with adequate excision margins

TABLE 2. Placement success and retrieval success of 22 magnetic seed markers in 21 patients*

\begin{tabular}{|c|c|}
\hline Final target-to-seed distance, $\mathrm{mm} \dagger$ & $3.1 \pm 9.8$ \\
\hline$\leq 1 \mathrm{~mm} \ddagger$ & $17(77.3 \%)$ \\
\hline $2-5 \mathrm{~mm}$ & $3(13.6 \%)$ \\
\hline $6-9 \mathrm{~mm}$ & 0 \\
\hline $\begin{array}{l}\geq 10 \mathrm{~mm} \text { (considered as significant } \\
\text { migration) }\end{array}$ & $2(9.1 \%)$ \\
\hline Placement success & $20(90.9 \%)$ \\
\hline Retrieval success & $22(100 \%)$ \\
\hline \multicolumn{2}{|c|}{$\begin{array}{l}\text { Data are shown as mean } \pm \text { standard deviation or No. (\%), } \\
\text { unless otherwise specified } \\
\text { The largest distance between target lesion and marker on } \\
\text { any plane } \\
\text { + Defined as markers essentially contacting the targets }\end{array}$} \\
\hline
\end{tabular}

migration on the day of surgery. This illustrates that delayed migration is unlikely to occur and it may not be necessary for patients to come back to the Radiology Department on the day of surgery to confirm magnetic seed marker position prior to the operation. Similar results were reported by a multicentre open-label cohort study on mastectomy patients, which showed no migration of magnetic seed markers between placement and surgery, which were up to 30 days apart. ${ }^{20}$ This reassures the feasibility of decoupling of surgery and radiology appointments, which can potentially reduce localisation-related delay in surgery. Prolonged fasting before surgery and the associated increased risk of vasovagal syncope can therefore be avoided. ${ }^{9}$ 
Magnetic seed markers are approved to be placed up to 30 days prior to surgery in Hong Kong at the time this article was written. However, successful retrieval was achieved in one of our patients who had had her surgery deferred to 56 days after magnetic seed marker placement due to personal reasons. This suggests that magnetic seed markers may be applicable for long-term implantation, which has already been approved in the United States and Europe.

Due to limitations of signal transmission, magnetic seed markers are intended to be placed at a depth up to $3 \mathrm{~cm}$ from skin according to the manufacturer's instructions. ${ }^{13}$ It is challenging to estimate the true lesion depth as the intraoperative breast position varies from the position during breast examinations, particularly when the breast is under compression during mammographic examinations. The distance from skin on the image does not necessarily reflect the shortest distance to the lesion and can be overestimated. Therefore, for lesions visible only on mammography, we selected those near the skin or at middle depth on mammography. For ultrasound-detected lesions, the sonographic depth of the lesion from the skin would be measured. We performed sonographic measurements for magnetic seed marker depth for all patients as the sonographic breast position should best resemble its intraoperative position. In our study, the depth of magnetic seed marker placement in successfully localised lesions ranged from 3 to $21 \mathrm{~mm}$ with a mean of $10.8 \mathrm{~mm}$. All magnetic seed markers were able to be localised by the probe intraoperatively. The depth limitation of magnetic seed markers is probably not a major issue in the Chinese population, since Chinese females tend to have thinner breasts. ${ }^{23}$ Further study is warranted to validate this postulation.

Because of potential signal interference, two magnetic seed markers should not be placed at close proximity $\left(<2 \mathrm{~cm}\right.$ apart) within the breast. ${ }^{14,20}$ This can potentially limit its use in bracketing a target or in localising multiple target lesions in one breast. We had one case requiring two magnetic seed markers placed in the same breast for bracketing a group of microcalcifications. Although one of them showed significant migration from the initial target, the final distance between the two magnetic seed markers was $29 \mathrm{~mm}$. Since there could be potential interference to the probe from hookwires, the target lesion and the non-migrated magnetic seed marker were first removed by hookwire guidance, and the migrated magnetic seed marker was then detected by the probe and removed. The utility of multiple magnetic seed markers in one breast should be further evaluated in future studies with larger sample sizes.

In our study, two magnetic seed markers (9.1\%) were found to have undergone significant migration of $\geq 10 \mathrm{~mm}$ from the target on post-insertion images. Both of them migrated along the direction of breast compression after the compression was released, with no significant hematoma detected radiologically or clinically. We postulate such migration to be resulting from the accordion effect, which is a well-known cause for clip migration after stereotactically guided biopsy. Fatty breasts are known to be more susceptible to accordion effectrelated migration as they are more compressible and are usually compressed to a greater degree. ${ }^{24}$ The migrated biopsy marker can move in the direction of compression either proximal or distal to the needle track when the breast expands to its original size and shape after compression. ${ }^{25-28}$ It is best evaluated in the plane orthogonal to the direction of compression used. ${ }^{25}$ Such migration was also recognised in 5.9\% of tomosynthesis-guided magnetic seed marker localisation procedures by a previous study. ${ }^{17}$ For prevention, it is suggested to hold and release the breast slowly from the compression pad after marker placement. ${ }^{17}$ Chinese patients probably have a lower risk of accordion effect-related migration, as they tend to have denser breasts. ${ }^{23}$ However, it could not be analysed in our study given our small sample size with only seven magnetic seed markers placed under stereotactic guidance. Future research with a larger sample size is needed to evaluate the association between breast density and seed migration.

There are several other drawbacks of magnetic seed marker localisation. Cost is a major concern as it is more expensive compared with hookwire or ROLL. Extra costs are needed for the initial purchase of the probes and instruments, ${ }^{17}$ as specialised nonferromagnetic surgical instruments must be used to avoid magnetic interaction between magnetic seed marker and sensor. However, minimising localisation-related delay in surgery may reduce the operational cost and improve workflow efficiency. A full cost analysis is necessary in the future. In addition, magnetic seed markers could not be placed under magnetic resonance imaging (MRI) guidance as the deployment needle is made of stainless steel. Magnetic seed marker insertion is contra-indicated for patients who have pacemakers or implanted cardiac devices due to interference of the devices with the probe. ${ }^{29}$ Magnetic seed markers are not officially indicated for use in nickel allergy patients. Bone wax, which is used as a terminal plug in the deployment needle, contains beeswax, and may cause allergic or foreign body reaction. ${ }^{13}$ Magnetic seed marker deployment is also not advised in a patient who may undergo future breast MRI prior to surgery due to its void artefact of 4 to $6 \mathrm{~cm}$ distance, ${ }^{5,9}$ which influences the MRI diagnostic accuracy. ${ }^{5}$

There are several limitations to this study. It is a single-institution retrospective study without direct comparison to our hookwire localisation or ROLL cases. Patients were selected for magnetic seed 
marker localisation in a multidisciplinary meeting involving breast radiologists and breast surgeons and this might introduce selection bias. We did not have any patients with a preoperative diagnosis of invasive carcinoma in our study, as sentinel node and occult lesion localisation with a radioisotope still remains the preferred localisation method for invasive carcinoma requiring sentinel lymph node biopsy in our centre. This can be performed in one single procedure instead of two, thus minimising patients' discomfort and potential complications from the procedure. However, magnetic seed markers have been reported to be a safe and feasible method for image-guided excision of invasive carcinoma. ${ }^{14,17,18}$ As discussed before, our small sample size limited our analyses of migration and margin clearance rates, and the evaluation of the feasibility of using multiple seeds in one breast for bracketing a lesion or for localising multiple lesions. A prospective randomised trial with larger sample size will be necessary to fully compare wire localisation and ROLL to magnetic seed marker localisation. Patient satisfaction, the reproducibility operator dependence of magnetic seed marker deployment and intraoperative localisation, specimen weight, and cosmetic outcome can also be investigated in future studies.

\section{Conclusion}

The magnetic seed marker system demonstrated safety and efficacy in Chinese women to localise and excise non-palpable breast lesions and appears to overcome many of the limitations of conventional localisation techniques. It can be an alternative to hookwires or ROLL in selected patients. Future research is needed to validate the results.

\section{Author contributions}

Concept or design: WY Fung, T Wong, CM Chau, ELM Yu. Acquisition of data: WY Fung.

Analysis or interpretation of data: WY Fung, T Wong, CM Chau, ELM Yu, JKF Ma.

Drafting of the manuscript: WY Fung, T Wong, CM Chau, ELM Yu.

Critical revision of the manuscript for important intellectual content: All authors.

\section{Conflicts of interest}

All authors have disclosed no conflicts of interest.

\section{Acknowledgement}

We would like to express our gratitude to our breast team (Department of Surgery, Princess Margaret Hospital) for support of our research project.

\section{Funding/support}

This research received no specific grant from any funding agency in the public, commercial, or not-for-profit sectors.

\section{Ethics approval}

This study was approved by Kowloon West Cluster Research Ethics Committee (Ref 146-11). The need for patient consent was waived by the Research Ethics Committee.

\section{References}

1. Lui CY, Lam HS, Chan LK, et al. Opportunistic breast cancer screening in Hong Kong; a revisit of the Kwong Wah Hospital experience. Hong Kong Med J 2007;13:10613.

2. Lau SS, Cheung PS, Wong TT, Ma MK, Kwan WH. Comparison of clinical and pathological characteristics between screen-detected and self-detected breast cancers: a Hong Kong study. Hong Kong Med J 2016;22:202-9.

3. Welch HG, Prorok PC, O'Malley AJ, Kramer BS. Breastcancer tumor size, overdiagnosis, and mammography screening effectiveness. N Engl J Med 2016;375:1438-47.

4. Ramos M, Díez JC, Ramos T, Ruano R, Sancho M, González-Orús JM. Intraoperative ultrasound in conservative surgery for non-palpable breast cancer after neoadjuvant chemotherapy. Int J Surg 2014;12:572-7.

5. Hayes MK. Update on preoperative breast localization. Radiol Clin North Am 2017;55:591-603.

6. Chu TY, Lui CY, Hung WK, Kei SK, Choi CL, Lam HS. Localisation of occult breast lesion: a comparative analysis of hookwire and radioguided procedures. Hong Kong Med J 2010;16:367-72.

7. Dauphine C, Reicher JJ, Reicher MA, Gondusky C, Khalkhali I, Kim M. A prospective clinical study to evaluate the safety and performance of wireless localization of nonpalpable breast lesions using radiofrequency identification technology. AJR Am J Roentgenol 2015;204:W720-3.

8. Sharek D, Zuley ML, Zhang JY, Soran A, Ahrendt GM, Ganott MA. Radioactive seed localization versus wire localization for lumpectomies: a comparison of outcomes. AJR Am J Roentgenol 2015;204:872-7.

9. Kapoor MM, Patel MM, Scoggins ME. The wire and beyond: recent advances in breast imaging preoperative needle localization. Radiographics 2019;39:1886-906.

10. Cheang E, Ha R, Thornton CM, Mango VL. Innovations in image-guided preoperative breast lesion localization. Br J Radiol 2018;91:20170740.

11. Ocal K, Dag A, Turkmenoglu O, Gunay EC, Yucel E, Duce MN. Radioguided occult lesion localization versus wire-guided localization for non-palpable breast lesions: randomized controlled trial. Clinics (Sao Paulo) 2011;66:1003-7.

12. Manca G, Mazzarri S, Rubello D, et al. Radioguided occult lesion localization: technical procedures and clinical applications. Clin Nucl Med 2017;42:e498-e503.

13. Endomag Ltd. Magseed ${ }^{\circ}$ magnetic marker system: Instructions for use. 2017. Available from: https://www. endomag.com/magseed/overview/. Accessed 30 Mar 2020.

14. Price ER, Khoury AL, Esserman LJ, Joe BN, Alvarado MD. Initial clinical experience with an inducible magnetic seed system for preoperative breast lesion localization. AJR Am J Roentgenol 2018;210:913-7.

15. Wilson EB. Probable inference, the law of succession, and statistical inference. J Am Stat Assoc 1927;22:209-12.

16. Sibbering M, Watkins R, Winstanley J, Patnick J, editors. Quality Assurance Guideline for Surgeons in Breast Cancer Screening (NHSBSP Publication No. 20). 4th ed. Sheffield: 
NHS Cancer Screening Programmes; 2009.

17. Lamb LR, Bahl M, Specht MC, D’Alessandro HA, Lehman $C D$. Evaluation of a nonradioactive magnetic marker wireless localization program. AJR Am J Roentgenol 2018;211:940-5.

18. Thekkinkattil D, Kaushik M, Hoosein MM, et al. A prospective, single-arm, multicentre clinical evaluation of a new localisation technique using non-radioactive Magseeds for surgery of clinically occult breast lesions. Clin Radiol 2019;74:974.e7-11.

19. Zacharioudakis K, Down S, Bholah Z, et al. Is the future magnetic? Magseed localisation for non palpable breast cancer. A multi-centre non randomised control study. Eur J Surg Oncol 2019;45:2016-21.

20. Harvey JR, Lim Y, Murphy J, et al. Safety and feasibility of breast lesion localization using magnetic seeds (Magseed): a multi-centre, open-label cohort study. Breast Cancer Res Treat 2018;169:531-6.

21. Fusco R, Petrillo A, Catalano O, et al. Procedures for location of non-palpable breast lesions: a systematic review for the radiologist. Breast Cancer 2014;21:522-31.

22. Nadeem R, Chagla LS, Harris O, et al. Occult breast lesions: a comparison between radioguided occult lesion localisation (ROLL) vs. wire-guided lumpectomy (WGL). Breast 2005;14:283-9.

23. Maskarinec G, Meng L, Ursin G. Ethnic differences in mammographic densities. Int J Epidemiol 2001;30:959-65.

24. Rosen LE, Vo TT. Metallic clip deployment during stereotactic breast biopsy: Retrospective analysis. Radiology 2001;218:510-6.

25. Burbank F, Forcier N. Tissue marking clip for stereotactic breast biopsy: initial placement accuracy, long-term stability, and usefulness as a guide for wire localization. Radiology 1997;205:407-15.

26. Liberman L, Dershaw DD, Morris EA, Abramson AF, Thornton CM, Rosen PP. Clip placement after stereotactic vacuum-assisted breast biopsy. Radiology 1997;205:417-22.

27. Esserman LE, Cura MA, DaCosta D. Recognizing pitfalls in early and late migration of clip markers after imagingguided directional vacuum-assisted biopsy. Radiographics 2004;24:147-56.

28. Endomag Ltd. Sentimag ${ }^{\circ}$ : instructions for use. 2018. Available from: https://www.endomag.com/sentimag/. Accessed 30 Mar 2020. 